\title{
Effect of habitat productivity and exploitation on populations with complex life cycles
}

\author{
K. E. van de Wolfshaar ${ }^{1,4, *}$, R. HilleRisLambers ${ }^{2}$, A. Gårdmark ${ }^{3}$ \\ ${ }^{1}$ Aquaculture and Fisheries Group, Wageningen University, 6709 PG, Wageningen, The Netherlands \\ ${ }^{2}$ Oceans \& Coasts Program, World Wildlife Fund, PO Box 7, 3700 AA Zeist, The Netherlands \\ ${ }^{3}$ Swedish Board of Fisheries, Institute of Coastal Research, 74242 Öregrund, Sweden \\ ${ }^{4}$ Present address: Institute for Marine Resource and Ecosystem Studies (IMARES), Wageningen UR, Haringkade 1, \\ 1976 CP, IJmuiden, The Netherlands
}

\begin{abstract}
In this paper we study the consequences of habitat switching and the corresponding ontogenetic diet shifts between adult and juvenile life stages for harvesting and management of exploited populations using a consumer-resource model with stage-specific mortality. Specifically, we study how differences in stage-specific habitat productivity regulate exploited populations and affect yield. We show that the ratio of adult to juvenile habitat productivity determines whether the population is regulated by processes in the juvenile or adult stage and that population responses to changes in mortality (e.g. fishing) or habitat productivity (e.g. eutrophication or physical destruction) depend critically on the mechanism regulating the population. This result has important consequences for the management of marine fish. For example, in fisheries where the exploited population is regulated by processes in the juvenile stage, management measures aimed at protecting the juvenile habitat may be much more effective than regulating fishing effort on the adults. We find also that intermediate differences in habitat productivity lead to alternative stable states between a population regulated by processes in the juvenile or the adult stage. These alternative stable states may lead to counterintuitive population responses to harvesting.
\end{abstract}

KEY WORDS: Alternative stable state - Density dependence - Habitat shift • Harvesting • Mortality · Productivity · Fisheries management

\section{INTRODUCTION}

Habitat shifts are a common feature of many species' life histories (Werner \& Gilliam 1984). These habitat shifts are often accompanied by morphological and physiological changes, which affect an individual's preference for different food sources, and its susceptibility to predation. Ontogenetic habitat shifts may directly affect individual growth and mortality, promote intra-specific competition within a life stage, and link spatially separated food webs (Wilbur 1988, McCoy et al. 2009). Shifts in habitat between life stages of a species may therefore have important con- sequences for its population dynamics, and thereby also for its responses to anthropogenic impacts such as harvesting (mortality) and eutrophication (food availability).

Many marine fish of commercial interest shift habitats between different life stages. For example, flatfish, such as Pleuronectes platessa or Solea solea in the North Sea, use estuaries as juveniles but switch to offshore demersal grounds as adults (Rijnsdorp \& Vingerhoed 2001), groupers, such as Epinephelus striatus, switch between sea grass beds and pelagic habitats (Dahlgren \& Eggleston 2001), while many salmonid species switch between rivers and ocean 
(e.g. Pacific salmon species, Bradford 1995). Despite their common occurrence in nature (Sears et al. 2004, Able 2005), the implications of such habitat shifts for the population dynamics and management of marine fisheries have received little attention, and as a result, theory for the management of marine fish undergoing ontogenetic habitat shifts is still in its infancy (St Mary et al. 2000, Gårdmark et al. 2006).

Recent evidence suggests that stage-specific, density-dependent processes may induce alternative stable states (Folke et al. 2004, Persson et al. 2007). In such case, changes in mortality in one stage may induce a rapid shift from one stable state to the other, leading to a counterintuitive change in overall abundance of a harvested population (Persson et al. 2007). Shifts in habitat use between life stages may therefore also lead to alternative stables states (Schreiber \& Rudolf 2008, Guill 2009). This suggests that management actions may have very different effects on exploited fish with stage-specific habitat shifts than on fish with habitat overlap throughout ontogeny. For example, the effectiveness of Marine Protected Areas (MPAs) in increasing overall abundance of harvestable life stages has been shown to depend on density-dependent interactions within other stages not of direct interest for management (Dugan \& Davis 1993, St. Mary et al. 2000, Claessen et al. 2009). Processes within stages without commercial interest are thus also likely to influence fishing mortality effects in exploited stages.

The effects of protecting habitats from fishing for particular life stages of an exploited population have been studied (e.g. St. Mary et al. 2000), as well as population dynamical effects of stage-specific habitat use (Schreiber \& Rudolf 2008, Guill 2009). However, how fisheries management acting on mortality versus on key fish habitats affects exploited species that switch habitats is not known.

In this paper we specifically address the links between habitat switching, habitat productivity, fishing mortality, and population dynamics from a theoretical perspective. We use a stage-structured biomass model that accounts for individual-level processes to analyze (1) how differences in stagespecific mortalities (e.g. exploitation) and differences in productivity between juvenile and adult habitats regulate population dynamics and (2) how differences in population regulation affect biomasses and yields. We place our results in a setting of field examples of harvested fish populations and explore the potential consequences of different types of population regulation for the impact of fishing and habitat restoration on exploited species.

\section{METHODS}

To study how differences in availability in juvenile and adult resources affect population dynamics we adopt the biomass-based stage-structured model introduced by de Roos et al. (2007, 2008). This model is a simplification of a more complex physiologically structured population model. The framework of physiologically structured population models (de Roos et al. 1992) was specifically designed to analyze the consequences of food-dependent individual growth and reproduction for population dynamics. The major advantage of the biomass-based stagestructured models is their amenability to conventional analysis techniques while maintaining identical equilibrium population state solutions as the complex model (de Roos et al. 2007, 2008). Below we describe the key biological features of the model; for a detailed mathematical derivation of the model equations we refer to de Roos et al. $(2007,2008)$.

The model contains a consumer population with a juvenile stage $(J)$, an adult stage $(A)$, and their resources. We introduce a second resource to the stage-structured population model of de Roos et al. (2007, 2008), so that juveniles and adults each feed on a different resource $\left(R_{\mathrm{J}}\right.$ and $R_{\mathrm{A}}$, respectively) corresponding to their different choices in habitat. This implies that juveniles and adults no longer compete for food. We assume that resources follow semichemostat dynamics, with growth rate $(\delta)$ and populations equilibrating at carrying capacity $\left(R_{\mathrm{CJ}}\right.$ and $R_{\mathrm{CA}}$ for the juvenile and adult resource, respectively) when consumers are absent. Juveniles and adults forage following a Holling Type II functional response with a half-saturation constant $(H)$ and a mass-specific maximum ingestion rate $\left(I_{\max }\right)$ (de Roos et al. 2007). For reasons of simplicity we assume that the maximum ingestion rate for adults and juveniles is equal. The ingested resources by each stage $(i)$, converted with an efficiency $(\sigma)$ minus the species massspecific metabolic rate $(T)$, then gives the net biomass production $\left(v_{i}\left(R_{i}\right)\right)$ of that stage when feeding on a particular resource $\left(R_{i}\right)$ :

$$
v_{i}\left(R_{i}\right)=\sigma I_{\max }\left(R_{i} /\left(H+R_{i}\right)\right)-T
$$

The following set of differential equations then describes the dynamics of the 2 exclusive resources $\left(R_{\mathrm{J}}\right.$ and $\left.R_{\mathrm{A}}\right)$ and juvenile and adult biomass:

$$
\begin{gathered}
\mathrm{d} R_{\mathrm{A}} / \mathrm{d} t=\delta\left(R_{\mathrm{CA}}-R_{\mathrm{A}}\right)-\left(R_{\mathrm{A}} /\left(H+R_{\mathrm{A}}\right)\right)\left(I_{\max } A\right) \\
\mathrm{d} R_{\mathrm{J}} / \mathrm{d} t=\delta\left(R_{\mathrm{CJ}}-R_{\mathrm{J}}\right)-\left(R_{\mathrm{J}} /\left(H+R_{\mathrm{J}}\right)\right)\left(I_{\max } J\right) \\
\mathrm{d} J / \mathrm{d} t=v_{\mathrm{A}}^{+}\left(R_{\mathrm{A}}\right) A+v_{\mathrm{J}}\left(R_{\mathrm{J}}\right) J-\gamma\left(v_{\mathrm{j}}^{+}\left(R_{\mathrm{J}}\right)\right) J-d_{\mathrm{J}} J
\end{gathered}
$$




$$
\mathrm{d} A / \mathrm{d} t=v_{\mathrm{A}}\left(R_{\mathrm{A}}\right) A-v_{\mathrm{A}}{ }^{+}\left(R_{\mathrm{A}}\right) A+\gamma\left(v_{\mathrm{j}}^{+}\left(R_{\mathrm{J}}\right)\right) J-d_{\mathrm{A}} A
$$

where $d_{i}$ is the mortality rate in stage $i, \gamma\left(v_{\mathrm{J}}{ }^{+}\left(R_{\mathrm{J}}\right)\right)$ is the rate at which juveniles mature into the adult stage, and $v_{\mathrm{A}}{ }^{+}\left(R_{\mathrm{A}}\right)$ is the reproduction rate.

The maturation rate of juveniles depends on the net biomass production of the juvenile stage, the size range over which juveniles grow from egg to adult, and juvenile mortality:

$$
\gamma\left(v_{\mathrm{j}}^{+}\left(R_{\mathrm{J}}\right)\right)=\left(v_{\mathrm{J}}\left(R_{\mathrm{J}}\right)-d_{\mathrm{J}}\right) /\left(1-z^{\wedge}\left(1-d_{\mathrm{J}} / v_{\mathrm{J}}\left(R_{\mathrm{J}}\right)\right)\right)
$$

with $z$ being the ratio between the individual body size at birth and at maturation (de Roos et al. 2007). We assumed that all surplus adult biomass is converted into offspring and hence that the reproduction rate equals the net biomass production of adults. Biomass can only be transferred between stages when net biomass is produced (i.e. $v_{\mathrm{i}}\left(R_{\mathrm{i}}\right)>0$, such that negative reproduction and maturation do not occur). If net biomass production is negative the stage suffers from starvation mortality, and neither recruitment nor maturation takes place (i.e. $v_{\mathrm{A}}{ }^{+}\left(R_{\mathrm{A}}\right)=0$, $\left.\gamma\left(v_{\mathrm{J}}^{+}\left(R_{\mathrm{J}}\right)\right)=0\right)$.

Adults and juveniles suffer from stage-specific mortality, $d_{\mathrm{A}}$ or $d_{\mathrm{J}}$, respectively. The causes of mortality are not defined as such, and can be considered as natural, e.g. disease and predation mortality, or caused by harvesting. We will address the consequences of mortality in general, and we investigate the effect of relative habitat productivity and stage-specific mortality on fisheries yields. Yield $(Y)$ is defined as the biomass of adults removed due to adult mortality $\left(d_{\mathrm{A}} \times A\right)$.

We additionally explored the consequences of migration mortality, which occurs during egg and larval drift from spawning areas (here in the adult habitat) to feeding grounds (here the juvenile habitat) and as a result from juvenile migration to the adult habitat when mature. We thereby assumed that migration mortality is a biomass loss for the receiving stage but does not influence competition in the source stage. The results of varying migration mortality are similar to those of the stage-specific mortality within habitats, i.e. $d_{\mathrm{A}}$ and $d_{\mathrm{J}}$, and will therefore not be discussed.

To explore the consequences of differences in productivity between juvenile and adult habitats, we assumed a baseline resource carrying capacity for both habitats of $R_{\max }$ and use a single parameter $(x)$ to scale the relative resource productivity of the 2 habitats by calculating the carrying capacities of the resource in the juvenile and adult habitat, respectively, according to the following formulae:

$$
\begin{gathered}
R_{\mathrm{CJ}}=\mathrm{e}^{\mathrm{x}} R_{\max } \\
R_{\mathrm{CA}}=\left(1 / \mathrm{e}^{x}\right) R_{\max }
\end{gathered}
$$

This means that at $x=0$, juvenile and adult habitats are equally productive. When $x<0$, the adult habitat is relatively more productive than the juvenile habitat, while when $x>0$, the juvenile habitat is relatively more productive. Differences in natural habitats depend on both productivity and habitat size. To simplify analysis, however, we assumed that differences between habitats are solely dependent on the differences in resource productivities between habitats as defined in Eqs. (7) \& (8), thereby keeping habitat sizes equal (McCoy et al. 2009). The relative difference in habitat productivity as a function of scalar $x$ is shown in Fig. 1.

Maintenance and ingestion are mass-specific rates proportional to the quarter power of adult body sizes (Yodzis \& Innes 1992), and the constants of the power laws are based on ectothermic species (de Roos et al. 2007, 2008, Guill 2009). Here, only juvenile and adult mortality and relative resource productivity were varied (Table 1). A sensitivity test was done to ensure that the model results are qualitatively robust against changes in parameter values. We confirm that varying the ratio between size at birth and size at maturation $(z)$, the maximum ingestion rate $\left(I_{\max }\right)$, the metabolic rate $(T)$ or the baseline resource carrying capacity $\left(R_{\max }\right)$ does not qualitatively alter the general patterns we found regarding the presence of alternative stable states and population persistence. However, if the ingestion rate approaches the metabolic rate, the minimum resource requirements increase until they can no longer be satisfied and the population ceases to exist. In contrast, when the ratio



Fig. 1. Ratio between the maximum juvenile resource carrying capacity $\left(R_{\mathrm{CJ}}\right)$ and the maximum adult resource carrying capacity $\left(R_{\mathrm{CA}}\right)$ as function of relative habitat productivity $(x)$ 
Table 1. Model variables and parameters. Parameter values are for ectothermic species (de Roos et al. 2007, 2008, Guill 2009). Subscript $i$ indicates juvenile or adult stage

\begin{tabular}{|lccl|}
\hline $\begin{array}{l}\text { Variable or } \\
\text { parameter }\end{array}$ & Value & Unit & Description \\
\hline$A$ & & & \\
$J$ & - & $\mathrm{g}$ & Adult biomass \\
$R_{\mathrm{A}}$ & - & $\mathrm{g}$ & Juvenile biomass \\
$R_{\mathrm{J}}$ & - & $\mathrm{g}$ & Adult resource \\
$\delta$ & - & $\mathrm{g}$ & Juvenile resource \\
$R_{\max }$ & 1 & $\mathrm{~g} \mathrm{~d}^{-1}$ & Resource turn-over rate \\
$R_{\mathrm{C} i}$ & 10 & $\mathrm{~g}$ & Maximum resource carrying capacity \\
$X$ & - & $\mathrm{g}$ & Resource carrying capacity of stage $i$ \\
$H$ & - & - & Relative habitat productivity scalar \\
$I_{\max }$ & 1 & - & Half saturation constant \\
$T$ & 13 & $\mathrm{~g} \mathrm{~g}^{-1} \mathrm{~d}^{-1}$ & Maximum ingestion rate \\
$\sigma$ & 1 & - & Metabolic rate \\
$d_{\mathrm{A}}$ & 0.7 & $\mathrm{~g} \mathrm{~g}^{-1}$ & Food conversion efficiency \\
$d_{\mathrm{J}}$ & Varied & $\mathrm{g} \mathrm{d}^{-1}$ & Adult mortality \\
$z$ & Varied & $\mathrm{g} \mathrm{d}^{-1}$ & Juvenile mortality \\
$v_{i}\left(R_{i}\right)$ & $1 \mathrm{e}^{-5}$ & - & Ratio body size at birth and maturation \\
$\gamma\left(\mathrm{v}_{\mathrm{J}}{ }^{+}\left(\mathrm{R}_{\mathrm{J}}\right)\right)$ & - & $\mathrm{g} \mathrm{d}^{-1}$ & Net biomass production of stage $i$ \\
\hline
\end{tabular}

On the other end of the relative productivity spectrum, when the juvenile habitat is much more productive than the adult habitat $(x \gg 0$, far right side of Fig. 2), juveniles experience little within-stage competition for resources. The relatively high availability of resources promotes growth and maturation of juveniles and leads to high adult biomass. The high adult biomass combined with a relatively low productivity in the adult habitat results in high resource competition within the adult stage. This population state is regulated by adult competition. We stress that while both 'juvenile competition regulation' and 'adult competition regulation' are density-dependent mechanisms for population regulation, these emerge from individual-level assumptions on between ingestion rate and metabolic rate increases, the minimum resource requirements decrease, which broadens the scope for population persistence and for the existence of alternative stable states. The wide range of parameter values for which the results hold implies that the results can be considered general for species exhibiting ontogenetic habitat shifts and that they are not limited to a particular parameter set belonging to specific species or groups of species. Moreover, Guill (2009) demonstrated for a similar model that changes in functional response and resource growth function do not affect the presence of alternative stable states.

\section{RESULTS}

\section{Changing relative productivity}

The strength of competition within a stage, relative to that within the other stage, changes with variation in the relative habitat productivity, $x$. When the adult habitat is very much more productive than the juvenile habitat ( $x \ll 0$, far left side of Fig. 2), populations are structured by high juvenile and low adult biomass, because adults rapidly transfer acquired energy into reproduction, resulting in many juveniles competing intensely for (scarce) resources. This intense competition for resources in the juvenile stage hampers maturation, resulting in a biomass build-up in the juvenile stage. This population state is regulated by juvenile competition. growth and reproduction in the presence of a limiting resource (de Roos et al. 2007, 2008, Guill 2009).

When the productivity of juvenile and adult habitats does not differ much $(-1.3<x<1.6)$ juvenile and adult competition regulated population states occur as alternative stable states (the parameter range is therefore called 'bistable'; Fig. 2). When the juvenile habitat is relatively more productive (i.e. for higher values of $x$ ), population cycling is also observed.

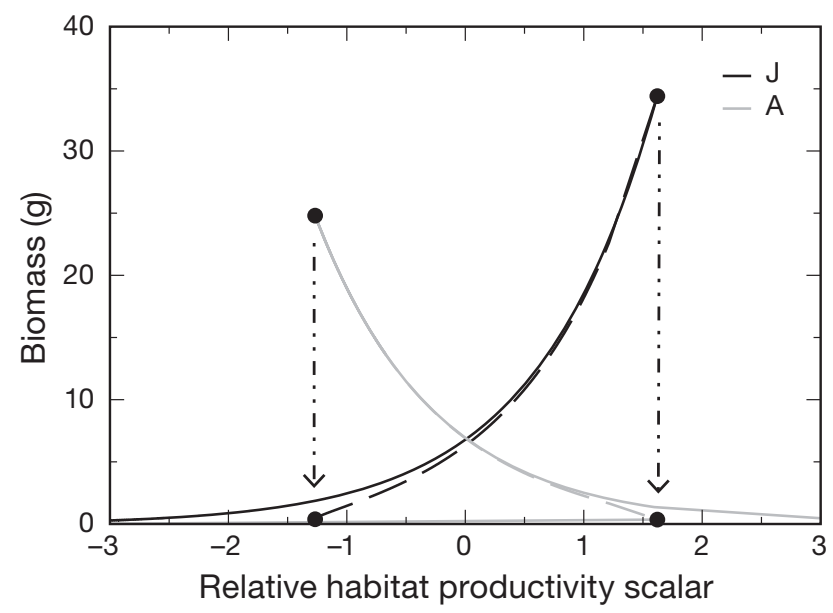

Fig. 2. Biomass of adult (A) and juvenile (J) life stages as function of relative habitat productivity $(x)$ showing where stages are under stable (solid lines) and unstable (dashed lines) equilibria. Alternative stable states occur between the collapses and beyond which only one stable equilibrium occurs. Adult $\left(d_{\mathrm{A}}\right)$ and juvenile mortality rate $\left(d_{\mathrm{J}}\right)$ parameters were both set to 0.05 hatched arrows, at which one of the alternative equilibria 
However, we will not discuss cyclic dynamics further, as the amplitude of these cycles is very small and their presence does not affect the qualitative nature of the results.

\section{Changing stage-specific mortality}

We studied the population response to changes in stage-specific mortality. When habitats are similarly productive $(-1.3<x<1.6)$, increasing mortality (juvenile or adult) eventually causes alternative stable states to disappear (Fig. 3a,b). An increase in mortality initially reduces resource competition in the stage that regulates the population, which leads to
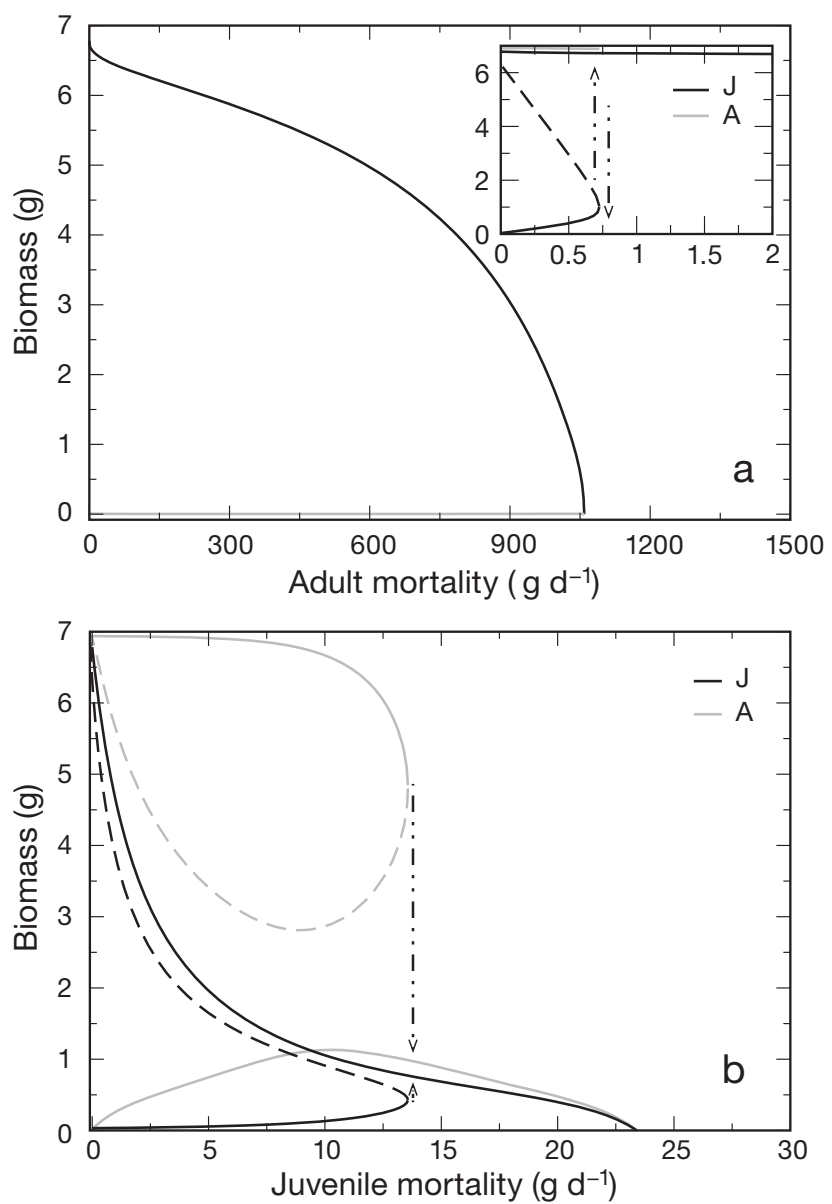

Fig. 3. Change in biomass of adults (A) and juveniles (J) as function of (a) adult mortality with juvenile mortality rate $\left(d_{\mathrm{J}}\right)$ set to 0.05 and (b) juvenile mortality with adult mortality rate $\left(d_{\mathrm{A}}\right)$ set to 0.05 for equal habitat productivity, showing where stages are under stable (solid lines) or unstable (dashed lines) equilibria. The hatched arrows indicate where one alternative stable equilibrium collapses with increasing mortality and beyond which only one stable equilibrium occurs. The inset is a detail of panel $\mathrm{a}$, showing juvenile and adult biomass at very low levels of adult mortality increased reproduction or maturation. This increase in reproduction or maturation results in a transfer of biomass from the stage that competition regulates the population to the stage that competition does not regulate the population. A further increase in mortality leaves only the juvenile competition regulated equilibrium, and eventually biomass in both stages decreases until the population can no longer persist (Fig. 3a). Alternative stable states prevail under much higher juvenile mortalities, when compared to under adult mortality (compare Fig. 3a with Fig. 3b).

\section{Changing relative productivity and mortality}

How does the combination of mortality and productivity conditions determine the occurrence of alternative stable states? When there are strong differences in productivity between adult and juvenile habitats (for $x<-4.8$ and $x>4.8$ in Fig. 4), the population is extremely sensitive to mortality, be it adult- or juvenile-specific. Alternative stable states occur when adult and juvenile habitat productivity does not differ much, although increased mortality limits the region of alternative stable states. Alternative stable states are more likely to occur with increased adult mortality when the juvenile habitat is more productive than the adult habitat $(x>0)$. In contrast, with increased juvenile mortality alternative stable states are more likely to occur when the adult habitat is more productive than the juvenile habitat $(x<0$; Fig. $4 a, c)$. This result is caused by the extent of the state regulated by adult competition defines the left hand side of the bistable area, whereas the extent of the state regulated by juvenile competition defines the right hand side of the bistable area (see Fig. 2). Both these states are limited by differences in relative habitat productivity and mortality. In the adult competition regulated state, raising productivity in the adult habitat relative to that in the juvenile habitat leads to reduced adult competition and increased reproduction. Increased reproduction in turn increases competition in the juvenile stage and hence decreases maturation to the point where maturation becomes limiting and the alternative state collapses towards the juvenile competition regulated state.

Juvenile mortality reduces competition in the juvenile habitat, thereby promoting persistence of the adult competition regulated state (Fig 4c). Adult mortality, on the contrary, increases reproduction and hence intensifies competition in the juvenile stage, causing the adult competition regulated state to collapse when juvenile habitats are relatively more pro- 



ductive than adult habitats (higher values of $x_{\text {; }}$ Fig. 4a). In the juvenile competition regulated state juvenile mortality increases the maturation rate to the adult stage, thereby intensifying adult competition. Thus, with higher juvenile mortality, the juvenile competition regulated state only occurs if productivity in the adult habitat increases (i.e. at lower values of $x_{i}$ Fig. $4 \mathrm{c}$ ). With increasing adult mortality the boundary of the juvenile competition regulated state shifts towards larger values of the relative habitat productivity scalar $(x)$ because adult mortality decreases the within-stage competition among adults (Fig. 4a).

\section{Exploitation}

We studied the effect of these underlying processes in an exploited population on the harvestable biomass (i.e. adult biomass) and biomass yields. Adult biomass increases when the juvenile habitat becomes relatively more productive and is highest in the bistable area when juvenile and adult habitat productivities are similar (Fig. 4b,d). Especially in case of (high) adult mortality, juvenile habitat productivity should be equal or higher than adult habitat productivity to ensure increased adult biomass (Fig 4b).

Increased harvesting evidently always increases yield (presented here as harvesting of adults) until optimal harvesting levels, whereas the effect of juvenile mortality on yield depends on the type of population regulation (Fig. 5). Contrary to expectations, in a juvenile competition regulated state, increased juvenile mortality results in an increased yield of adults due to the release of competition in the juvenile stage (Fig. 5a), which does not occur in an adult competition regulated state. The yield in the adult competition regulated state is higher than that in the juvenile competition regulated state as biomass is 'trapped' in the harvested stage (i.e. the adults; Fig. 5b). The highest yields in the adult competition regulated state, however, occur for lower adult harvesting rates

Fig. 4. (a,c) Equilibrium boundaries for extinction (blue line) and bistability (black line), and (b,d) adult biomass isoclines overlaid on equilibrium boundaries (dashed lines) as a function of habitat productivity $(x)$. $(\mathrm{a}, \mathrm{b})$ Adult mortality-habitat productivity plane for different levels of adult biomass $(A)$ when juvenile mortality rate $\left(d_{\mathrm{J}}\right)$ is set to 0.05 . (c,d) Juvenile mortality-habitat productivity plane for different levels of adult biomass $(A)$ when adult mortality rate $\left(d_{\mathrm{A}}\right)$ is set to 0.05 

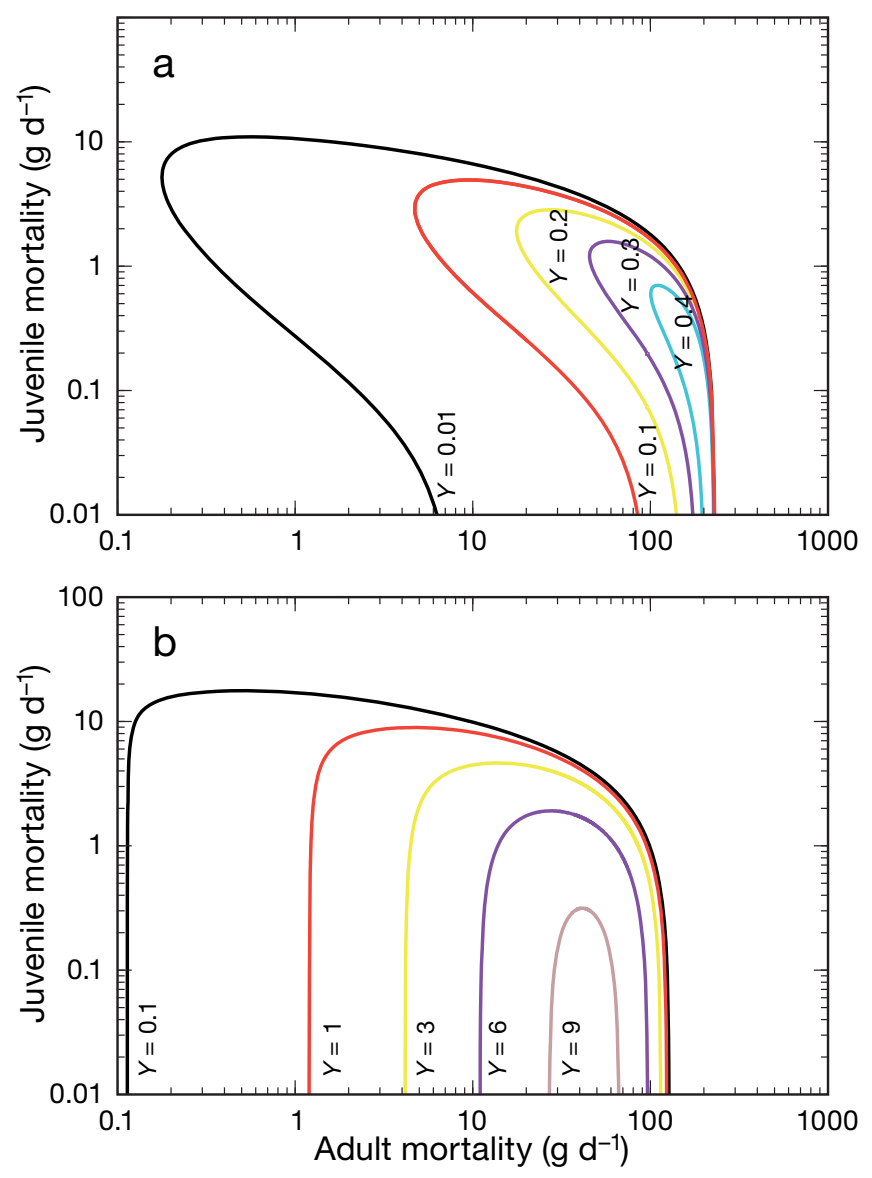

Fig. 5. Yield $(Y)$ isoclines in the adult-juvenile mortality parameter plane (a) in a juvenile competition regulated population with habitat productivity $(x)$ set to -2 , and (b) in an adult competition regulated population with habitat productivity $(x)$ set to 2

than those in the juvenile competition regulated state. In both cases, the steepest decline in yields and biomasses occurs due to increased exploitation beyond optimal harvesting levels, but the risk of extinction due to harvesting increases with juvenile mortality (Fig. 5).

As the relative habitat productivity affects the mechanism of population regulation, it also has a strong influence on yield (Fig. 6). Highest yields are obtained when the juvenile habitat is more productive than the adult habitat (i.e. $x>0$; Fig. 6). However, at very large differences in productivity, yields decline as the productivity of one of the habitats becomes limiting. Thus, yields depend on fishing mortality as well as habitat productivity (Fig. 6). Therefore, optimal yields may be obtained through changes in either habitat productivity or fishing (adult) mortality or both (Fig. 6).



Fig. 6. Yield $(Y)$ isoclines in the adult mortality habitat productivity $(x)$ parameter plane overlaid on to (dashed lines) equilibrium boundaries from Fig. 4 a with juvenile mortality rate $\left(d_{\mathrm{J}}\right)$ set to 0.05

\section{DISCUSSION}

Many aquatic species switch between habitats throughout their life cycle and thereby link energy flows between habitats (Mellin et al. 2007). We show that such ontogenetic habitat shifts lead to differences in population regulation, which may strongly influence the effects of population management. The type of population regulation - juvenile or adult competition regulation-depends on the relative productivity of adult and juvenile habitat. At intermediate differences in habitat productivity alternative stable states occur, so that the population is regulated by either process depending only on initial population abundances. We show that processes affecting stage-specific mortality or productivity in specific habitats (1) result in different effects on the population depending on its regulating process, (2) can force populations into alternative stable states and, thus, (3) may cause large and rapid changes in abundance in non-targeted habitats and population segments. Management of exploited populations should hence focus on the life stages that regulate the whole population through density dependence rather than those of direct commercial interest.

In this study we emphasize the effects of a difference in productivity between juvenile and adult habitats by assuming that no habitat overlaps between life stages. Although complete habitat segregation rarely occurs, species such as Norwegian springspawning herring Clupea harengus exhibit large habitat shifts; whereas adults inhabit and spawn in 
the northern Atlantic, juveniles drift to the Northeast Arctic, an area to which they never return as adults (Dragesund et al. 1997). A survey of reef fishes in the South Pacific shows that two-thirds of the species undergo an ontogenetic habitat shift. The larvae drift from the adult reef habitat to the nursery grounds and juveniles migrate back to the adult reef when reaching maturity (Mellin et al. 2007). Our results suggest that these populations are either regulated by juvenile or adult competition, depending on whether density-dependent regulation is strongest in the juvenile or adult habitats, respectively. Relaxing the assumption of strict habitat segregation limits migration mortality as ontogenetic shifts then operate on small spatial scales reducing travel time. However, even with complete habitat overlap ontogenetic diet shifts still allow for alternative population regulation based on resource productivity and stage-specific density dependence occurring then with a temporal component (Osenberg et al. 1992).

Switches between the 2 types of regulation have been reported to occur in fish species as a consequence of a sudden decrease of a competing or prey species, caused by natural and management events (Osenberg et al. 1992, Persson et al. 2007). Even when assuming no diet shift in time or space and all sizes compete for the same resource, difference in population regulation can still occur based on competitive differences between stages, although alternative states do not occur in this case (de Roos et al. 2007). Taken together, this suggests that divergent population responses to harvesting may occur commonly in species with stage-specific resource use due to alternative types of population regulation.

The result that population effects of decreasing mortality depend on habitat productivity and the resulting population regulation may have implications for rebuilding overexploited fish stocks. Our results imply that management of exploited fish populations should focus on the life stage with the strongest density-dependent regulation, i.e. on juveniles in juvenile competition regulated populations and on adults in adult competition regulated populations. When populations are driven by juvenile competition, i.e. when juveniles are resource limited, such as the flatfish populations in the North Sea (Iles \& Beverton 2000, Rijnsdorp \& Vingerhoed 2001), measures aiming to improve juvenile habitats will be more effective in increasing adult biomass than measures aiming at adult life stages (Fig. 4). A positive relationship between nursery size and abundance has been demonstrated on several occasions (Van der Veer et al. 2000, Aburto-Oropeza et al. 2007,
Claudet et al. 2008). In the case of adult competition regulation, i.e. when adults are resource limited, or when reproduction is hampered for other reasons such as low standing stock biomass, reducing fishing mortality can lead to increased biomass of harvestable sizes (Fig. 4a; Fiorentino et al. 2008), especially when protecting seasonally migrating adults at spawning sites (Kerwath et al. 2009). However, the recovery rate of adult competition regulated populations may be slower compared to juvenile competition regulated populations with limited juvenile habitats (Beverton 1995, Iles \& Beverton 2000).

Our results also demonstrate that habitat restoration may have a greater impact on the harvestable population than reducing fishing mortality, which is mainly the case at low exploitation levels but in some limited cases also at high fishing mortality (Fig. 6). Moreover, independent of exploitation levels (but in the absence of bistability), the highest adult biomass always occurs when juvenile habitats are relatively more productive than adult habitats. This pivotal role of habitat productivity demonstrates the need for integrated approaches to rebuilding overexploited fish stocks. In addition, it shows that management focusing purely on the exploited stage of fish stocks (typically adults) may only be effective when juvenile habitats are more productive than adult habitats.

Changing basic assumptions of our model on resource growth, consumer foraging function, and energy allocation do not affect the presence of alternative stable states (Schreiber \& Rudolf 2008, Claessen et al. 2009, Guill 2009). Moreover, Guill (2009) demonstrated that the existence of alternative stable states only depends on the ability of both stages to have overcompensation at high biomass densities, a requirement fulfilled when there is only within-stage competition. This explains why varying the ratio between size at birth and size at maturation, the maximum ingestion rate, the metabolic rate and the resource carrying capacity does not qualitatively alter the general patterns found in alternative stable states and population persistence (results not shown). The fact that the results hold for a large range of parameter values indicates that our findings are not limited to certain species but may be widely applicable, given that the condition of only within-stage resource competition is fulfilled. However, we expect that a reduction of the degree of between-stage competition, e.g. by plasticity in the size of juvenile migration to the adult habitat (Werner \& Gilliam 1984), will result in decreased potential for alternative stables states, but that is beyond the scope of the study presented here. 
Our results show the critical role of ontogenetic habitat shifts in determining the effectiveness of alternative fisheries and marine habitat management actions. However, little knowledge exists on how to recognize ontogenetic bottlenecks in exploited populations. We suggest that proxies for ontogenetic bottlenecks, such as condition factors of juveniles and adults may give an indication of whether a population is in a juvenile or adult competition regulated state. Once fully evaluated and developed, e.g. using physiologically based size-structured models (de Roos et al. 1992, van de Wolfshaar et al. 2006), such indicators may become useful tools for identifying whether management strategies for spatially segregated populations should focus on adult or juvenile stages or how to combine catch restrictions with habitat management. Our results show that such an integrated view on habitat productivity and exploitation and its effects on marine populations is needed for informed fisheries management.

Acknowledgements. K.E.W. is financed by The Netherlands Organization for Scientific Research, grant no. 857.00.011. The authors thank M. Heino for discussions, A. de Roos for his valuable comments on earlier versions of the manuscript and the anonymous reviewers for their comments.

\section{LITERATURE CITED}

Able KW (2005) A re-examination of fish estuarine dependence: evidence for connectivity between estuarine and ocean habitats. Est Coast Shelf Sci 64:5-17

> Aburto-Oropeza O, Sala E, Paredes G, Mendoza A, Ballesteros E (2007) Predictability of reef fish recruitment in a highly variable nursery habitat. Ecology 88:2220-2228

> Beverton RJH (1995) Spatial limitation of population size; the concentration hypothesis. Neth J Sea Res 34:1-6

> Bradford MJ (1995) Comparative review of Pacific salmon survival rates. Can J Fish Aquat Sci 52:1327-1338

> Claessen D, de Vos AS, de Roos AM (2009) Bioenergetics, overcompensation, and the source-sink status of marine reserves. Can J Fish Aquat Sci 66:1059-1071

> Claudet J, Osenberg CW, Benedetti-Cecchi L, Domenici P and others (2008) Marine reserves: size and age do matter. Ecol Lett 11:481-489

> Dahlgren CP, Eggleston DB (2001) Spatio-temporal variability in abundance, size and microhabitat associations of early juvenile Nassau grouper Epinephelus striatus in an off-reef nursery system. Mar Ecol Prog Ser 217:145-156

$>$ de Roos AM, Diekmann O, Metz JAJ (1992) Studying the dynamics of structured population models: a versatile technique and its application to Daphnia. Am Nat 139: 123-147

de Roos AM, Schellekens T, van Kooten T, van de Wolfshaar KE, Claessen D, Persson L (2007) Food-dependent growth leads to overcompensation in stage-specific biomass when mortality increases: the influence of maturation versus reproduction regulation. Am Nat 170:E59-E76

de Roos AM, Schellekens T, van Kooten T, van de Wolfshaar KE, Claessen D, Persson L (2008) Simplifying a physiologically structured population model to a stage-structured biomass model. Theor Popul Biol 73:47-62

Dragesund O, Johannessen A, Ulltang Ø (1997) Variation in migration and abundance of Norwegian spring spawning herring (Clupea harengus L.). Sarsia 82:97-105

Dugan JE, Davis GE (1993) Applications of marine refugia to coastal fisheries management. Can J Fish Aquat Sci 50: 2029-2042

- Fiorentino F, Badalamenti F, D'Anna G, Garofalo G and others (2008) Changes in spawning-stock structure and recruitment pattern of red mullet, Mullus barbatus, after a trawl ban in the Gulf of Castellammare (central Mediterranean Sea). ICES J Mar Sci 65:1175-1183

Folke C, Carpenter S, Walker B, Scheffer M, Elmqvist T, Gunderson L, Holling CS (2004) Regime shifts, resilience, and biodiversity in ecosystem management. Annu Rev Ecol Evol Syst 35:557-581

> Gårdmark A, Jonzén N, Mangel M (2006) Density-dependent body growth reduces the potential of marine reserves to enhance yields. J Appl Ecol 43:61-69

Guill C (2009) Alternative dynamical states in stagestructured consumer populations. Theor Popul Biol 76: 168-178

Iles TC, Beverton RJH (2000) The concentration hypothesis: the statistical evidence. ICES J Mar Sci 57:216-227

Kerwath SE, Thorstad EB, Næesje TF, Cowley PD, Økland F, Wilke C, Attwood CG (2009) Crossing invisible boundaries: the effectiveness of the Langebaan Lagoon Marine Protected Area as a harvest refuge for a migratory fish species in South Africa. Conserv Biol 23:653-661

> McCoy MW, Barfield M, Holt RD (2009) Predator shadows: complex life histories as generators of spatially patterned indirect interactions across ecosystems. Oikos 118: $87-100$

> Mellin C, Kulbicki M, Ponton D (2007) Seasonal and ontogenetic patterns of habitat use in coral reef fish juveniles. Est Coast Shelf Sci 75:481-491

> Osenberg CW, Mittelbach GG, Wainwright PC (1992) Twostage life histories in fish: the interaction between juvenile competition and adult performance. Ecology 73: 255-267

> Persson L, Amundsen PA, de Roos AM, Klemetsen A, Knudsen R, Primicerio R (2007) Culling prey promotes predator recovery-alternative states in a whole-lake experiment. Science 316:1743-1746

> Rijnsdorp AD, Vingerhoed B (2001) Feeding of plaice Pleuronectes platessa (L.) and sole Solea solea (L.) in relation to the effects of bottom trawling. J Sea Res 45:219-229

Schreiber S, Rudolf VHW (2008) Crossing habitat boundaries: coupling dynamics of ecosystems through complex life cycles. Ecol Lett 11:576-587

Sears ALW, Holt RD, Polis GA (2004) Feast and famine in food webs: the effects of pulsed productivity. In: Polis GA, Power ME, Huxel GR (eds) Food webs at the landscape scale: the ecology of trophic flow across habitats. University of Chicago Press, Chicago, IL, p 359-386

St. Mary CM, Osenberg CW, Frazer TK, Lindberg WJ (2000) Stage structure, density dependence and the efficacy of marine reserves. Bull Mar Sci 66:675-690

van de Wolfshaar KE, de Roos AM, Persson L (2006) Size- 
dependent interactions inhibit coexistence in intraguild predation systems with life-history omnivory. Am Nat 168:62-75

van der Veer HW, Berghahn R, Miller JM, Rijnsdorp AD (2000) Recruitment in flatfish, with special emphasis on North Atlantic species: progress made by the Flatfish Symposia. ICES J Mar Sci 57:202-215

- Werner EE, Gilliam JF (1984) The ontogenetic niche and

Editorial responsibility: Matthias Seaman,

Oldendorf/Luhe, Germany species interactions in size-structured populations. Annu Rev Ecol Syst 15:393-425

Wilbur H (1988) Interactions between growing predators and growing prey. In: Ebenman B, Persson L (eds) Sizestructured populations: ecology and evolution. Springer, Berlin, p 157-172

$>$ Yodzis P, Innes S (1992) Body size and consumer-resource dynamics. Am Nat 139:1151-1175

Submitted: May 17, 2011; Accepted: July 21, 2011

Proofs received from author(s): September 22, 2011 